\title{
Minimum Performance Requirements for Microbial Fuel Cells to Achieve Energy-Neutral Wastewater Treatment
}

\author{
Zachary A. Stoll ${ }^{1}$, Jan Dolfing ${ }^{2}$ (D) and Pei Xu ${ }^{1, *(\mathbb{D})}$ \\ 1 Department of Civil Engineering, New Mexico State University, Las Cruces, NM 88003, USA; \\ zstol19@gmail.com \\ 2 School of Engineering, Newcastle University, Newcastle upon Tyne NE1 7RU, UK; \\ jan.dolfing@newcastle.ac.uk \\ * Correspondence: pxu@nmsu.edu; Tel.: +1-575-646-5870
}

Received: 1 January 2018; Accepted: 24 February 2018; Published: 27 February 2018

\begin{abstract}
Microbial fuel cells (MFCs) have recently achieved energy-positive wastewater treatment at pilot scale. Despite these achievements, there is still a limited understanding as to whether all wastewaters contain sufficient amounts of energy and, if so, whether MFCs can capture a sufficient amount of energy to offset electrical energy requirements in the wastewater treatment process. Currently, there are no tools or methods available that can determine whether an MFC can be energy-neutral a priori. To address this, we derived a simple relationship by setting the electrical energy requirements of a wastewater treatment facility equal to the net energy output of the MFC, such that the resulting expression describes the minimum chemical oxygen demand (COD) removal needed to achieve energy-neutral treatment. The resulting equation is simply a function of electrical energy requirements, Coulombic Efficiency, and cell voltage. This work provides the first ever quantitative method for determining if the MFCs are feasible to achieve energy-neutral treatment for a given wastewater and what level of performance is needed.
\end{abstract}

Keywords: microbial fuel cell; wastewater treatment; energy-neutral treatment; water-energy; organic degradation; chemical oxygen demand removal; energy analysis; electrical energy demand

\section{Introduction}

Energy and water security have become global challenges in recent years due to climate change, water shortages, rising energy demand, and increasing material costs [1]. Water and wastewater treatment are expensive and energy intensive processes that collectively cost over $\$ 4$ billion [2], consuming $3-4 \%$ of the total U.S. energy budget each year [3]. Implementing more energy efficient treatment systems is seen as a strategy to simultaneously improve sustainability and reduce operating expenses. For example, a 10\% reduction in annual energy consumption would save 5 billion kilowatt-hours and $\$ 400$ million in energy costs [2]. With approximately half of a wastewater treatment plant's energy budget being used for aeration [4], implementing anaerobic treatment processes has been employed to significantly reduce treatment costs and energy consumption.

One emerging aeration-free treatment technology is the microbial fuel cell (MFC), which can treat wastewater and generate electricity at the same time. In the last decade, MFCs have been studied extensively in the laboratory, but so far only a few on-site pilot-scale $(>10 \mathrm{~L})$ bioelectrochemical systems have been built and tested, attaining varying levels of success [5-11]. Recent pilot studies have demonstrated that MFCs can be self-sufficient [5,7,12], in the sense that the energy captured from the MFCs could be used to power the feed and/or recirculation pump(s). 
Aside from pumping energy, there are additional electrical energy sinks within a wastewater treatment plant (WWTP) such as mixing (e.g., aerated grit chambers, biological aeration), filtration, disinfection and other ancillary needs such as lighting and monitoring. Because the oxidation of organics in the anode chamber of MFCs is an anaerobic process, the MFCs have the advantage of generating very little biomass. Indeed, researchers have observed sludge yields in MFCs ranging from 0.07 to $0.22 \mathrm{gVSS} / \mathrm{gCOD}$ (gram of volatile suspended solids per gram of chemical oxygen demand removed), which is lower than yields for aerobic systems (0.54 gVSS/gCOD) [13,14]. Therefore, sludge production should be minimal in MFCs, resulting in lower energy costs for sludge handling.

Despite being considered as a potential technology to achieve energy-neutral treatment, to the best of our knowledge, the MFC has not been explicitly considered in its ability to offset pumping and additional electrical energy sinks, leaving a knowledge gap as to how much energy an MFC would need to generate to be energy-neutral. At this time, no energy analysis framework exists for determining if MFCs can achieve energy-neutral treatment and the interdependency between the factors that determine performance and energy consumption has not been established. Therefore, it is not possible to answer questions such as: Is it more beneficial to have an MFC system with a $10 \%$ higher Coulombic Efficiency or a 10\% higher voltage? What is the minimum theoretical chemical oxygen demand (COD) removal needed to achieve energy-neutral treatment for a given reactor?

The purpose of this study is to begin to develop a quantitative understanding of what performance requirements are needed for an MFC to achieve energy-neutral treatment. We choose to evaluate energy-neutral wastewater treatment as minimum standard, because it represents a concrete point, where energy sinks equal energy sources, providing a well-defined baseline and minimum goal to aim for. In this paper, we develop a relationship that describes the COD removal needed in order for MFCs to achieve energy-neutral treatment based on the minimum cell voltage $\left(E_{M F C}\right)$ and Coulombic Efficiency (CE). We assume that the secondary aerobic treatment system is replaced by MFCs in a given facility and adopt values for electrical energy requirements based on literature values. We develop general equations for the MFC's energy output and then set this equal to the electrical energy requirements at the WWTP to describe energy-neutral treatment. With the resulting expression, the feasibility of attaining energy-neutral treatment is discussed, as well as new research opportunities.

\section{Materials and Methods}

\subsection{Steady-State Energy Sinks}

To begin the derivation, we assume a wastewater treatment plant with an influent lift station that pumps water to the entrance works with coarse screening and grit removal. Water flows by gravity to primary clarifiers, through the MFC module then to disinfection. We consider only the energy required for treatment within the facility and do not include energy required for collection and conveyance. The total energy use $\left(N_{W W T P}, T, \mathrm{kWh} /\right.$ day) can be calculated by multiplying the normalized energy usage $\left(N_{W W T P}, \mathrm{kWh} / \mathrm{m}^{3}\right)$ by the flow rate $\left(Q, \mathrm{~m}^{3} / \mathrm{s}\right)$ such that:

$$
N_{W W T P, T}=N_{W W T P} \cdot Q \cdot 86,400 \frac{s}{d}
$$

\subsection{Steady-State Energy and Power Generation}

We realize that an array of MFCs would be needed to treat large volumes of wastewater and that the MFCs would be configured and connected together in a way that optimizes performance. However, for the initial efforts of this paper, we will model a single MFC, assuming a mature biofilm with an air cathode treating wastewater at a steady state. The MFC power $\left(P_{M F C}, \mathrm{~W}\right)$ and energy generated $\left(N_{M F C}, \mathrm{kWh} /\right.$ day) can be expressed according to Logan et al. [15]:

$$
P_{M F C}=E_{M F C} \cdot I_{S S}
$$




$$
N_{M F C}=E_{M F C} \cdot I_{S S} \cdot t \cdot \frac{1 \mathrm{~kW}}{1000 \mathrm{~W}}
$$

where $E_{M F C}(\mathrm{~V})$ is the cell voltage, $I_{S S}$ is the steady-state current $(\mathrm{A})$ and $t$ is time (h/day).

The steady-state current for a continuous flow MFC can be derived from the definition of Coulombic Efficiency (CE) as described by Logan et al. [15]:

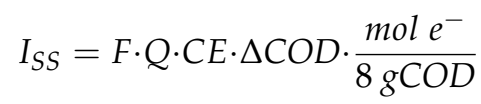

where $F$ is Faraday's constant $(96,485 \mathrm{C} / \mathrm{mol}), Q$ is the flow rate in $\mathrm{m}^{3} / \mathrm{s}, C E$ is a percent expressed as a decimal, and $\triangle C O D$ is in $\mathrm{g} / \mathrm{m}^{3}$. Thus,

$$
N_{M F C}=E_{M F C} \cdot F \cdot Q \cdot C E \cdot \triangle C O D \cdot \frac{m o l e^{-}}{8 g C O D} \cdot t \cdot \frac{1 \mathrm{~kW}}{1000 \mathrm{~W}}
$$

\subsection{Requirements for Energy-Neutral Wastewater Treatment}

To determine the conditions in energy-neutral treatment will occur, the WWTP energy utilization rate (Equation (1)) is set equal to the energy output rate from the MFC (Equation (5)) such that:

$$
\begin{gathered}
N_{W W T P, T}=N_{M F C} \\
N_{W W T P} \cdot Q \cdot 86,400 \frac{s}{d}=E_{M F C} \cdot F \cdot Q \cdot C E \cdot \Delta C O D \cdot \frac{m o l ~}{8} \frac{-}{8 C O D} \cdot \frac{1 k W}{1000 \mathrm{~W}} \cdot t
\end{gathered}
$$

Assuming the MFC runs for $24 \mathrm{~h}$ per day and that all the flow coming into the WWTP is treated by the MFC, the equation simplifies to

$$
N_{W W T P}=\zeta \cdot E_{M F C} \cdot C E \cdot \triangle C O D
$$

where the constant $\zeta=0.00345$ is the combined value of the constants on left and right-hand side of Equation (7), and has unit of $C \cdot \mathrm{kWh} \cdot \mathrm{s}^{-1} \cdot \mathrm{gCOD}^{-1} \cdot \mathrm{W}^{-1}$. This equation indicates that the MFC voltage (i.e., the difference in anode and cathode potentials), the $C E$ (moles of electrons transferred to the anode divided by total moles of electrons available) and $\triangle C O D$ removed (i.e., total moles of electrons available) are the variables that determine the MFC's energy output (kWh/day).

Solving for $\triangle C O D$ yields Equation (8), which expresses the minimum COD removal needed for energy-neutral treatment as a function of $N_{W W T P}, E_{M F C}$, and $C E$. We believe this equation is useful in determining if a given wastewater stream has sufficient energy for an MFC to capture and determine what performance the MFC must achieve (cell voltage and $C E$ ) in order to be energy-neutral.

$$
\triangle C O D=\frac{N_{W W T P}}{\zeta \cdot E_{M F C} \cdot C E}
$$

\section{Results and Discussion}

The purpose of this paper is to present a set of equations that can help determine what performance requirements needed to be energy-neutral, with the hopes that these equations will help determine if an MFC (or array of MFCs) can capture sufficient energy to offset energy demands at a wastewater treatment facility. The equations were developed in the previous section and the following sections determine: (1) the range of energy utilization at WWTPs $\left(N_{W W T P}\right)$; and (2) the performance range MFCs typically operate in (the $E_{M F C}, \triangle C O D$ and $C E$ parameters). Once the value range for each parameter is determined, they can be plugged into Equation (9) and the results are analyzed. 


\subsection{Energy Utilization at WWTPS}

Several independent sources have determined the electrical energy usage for WWTPs. Using data from the U.S Environmental Protection Agency (EPA) Star Energy's database, researchers from the Lawrence Berkeley National Lab (LBNL) calculated the weighted-based average energy consumption of WWTPs as a function of the design capacity [4]. For WWTPs producing less than $7750 \mathrm{~m}^{3}$ /day ( 2 million gallons per day, MGD), average energy intensity use is the highest and estimated to be $0.87 \mathrm{kWh} / \mathrm{m}^{3}$, whereas medium sized facilities with design capacities $27,000-60,500 \mathrm{~m}^{3} /$ day (7-16 MGD) consume less energy per unit volume of wastewater treated $\left(0.53 \mathrm{kWh} / \mathrm{m}^{3}\right)$. The largest facilities $\left(>60,500 \mathrm{~m}^{3} /\right.$ day) benefit the most from the economies of scale requiring only $0.42-0.45 \mathrm{kWh} / \mathrm{m}^{3}$, however, the law of diminishing returns is apparent, with WWTPs $>60,500 \mathrm{~m}^{3}$ /day not consuming considerably more energy per unit volume of wastewater treated than facilities over $378,500 \mathrm{~m}^{3} /$ day (100 MGD).

In comparison, Klein et al. surveyed several WWTPs in California and found the electrical energy use ranged from 0.53 to $0.78 \mathrm{kWh} / \mathrm{m}^{3}$. The California energy usage benchmark was also cited as being $0.69 \mathrm{kWh} / \mathrm{m}^{3}$ [16]. Yonkin et al. surveyed 174 WWTPs in New York State with capacities ranging from $<3785 \mathrm{~m}^{3} /$ day (1 MGD) to $>284,000 \mathrm{~m}^{3} /$ day $(75 \mathrm{MGD}$ ) and also determined the average electrical energy used as a function of design capacity [17]. For WWTPs producing less than $3785 \mathrm{~m}^{3} /$ day, average energy usage is significantly higher $\left(0.9 \mathrm{kWh} / \mathrm{m}^{3}\right)$ than the national average $\left(0.32 \mathrm{kWh} / \mathrm{m}^{3}\right)$ and all larger facilities $\left(0.28\right.$ to $\left.0.41 \mathrm{kWh} / \mathrm{m}^{3}\right)$. Averaging all of these values yields an electrical energy use of $0.58 \mathrm{kWh} / \mathrm{m}^{3}$.

It is known that approximately half of the energy consumption at a WWTP is due to the aeration energy requirements for oxidizing biochemical oxygen demand (BOD) and ammonia $\left(\mathrm{NH}_{3}\right)$ in the activated sludge process [4]. Typical design values for air needed to oxidize BOD and $\mathrm{NH}_{3}$ are $1.1 \mathrm{~kg}$ $\mathrm{O}_{2} / \mathrm{kg}$ BOD and $4.6 \mathrm{~kg} \mathrm{O}_{2} / \mathrm{kg} \mathrm{NH}_{3}$, respectively [18]. According to Metcalf and Eddy [19], the average BOD and $\mathrm{NH}_{3}$ concentrations for medium strength wastewater are 350 and $45 \mathrm{mg} / \mathrm{L}$, respectively. If it is assumed that the effluent $\mathrm{BOD}$ and $\mathrm{NH}_{3}$ values are 30 and $0 \mathrm{mg} / \mathrm{L}$ for surface water discharge, respectively, then for a given flow rate the energy required to oxidizing the BOD comprises $63 \%$ of the total aeration requirement. For this paper, we assume that MFCs will replace the activated sludge process and will offset the BOD aeration requirements, but not the ammonia aeration requirements. Therefore, the electrical energy requirements of a WWTP using an MFC instead of activated sludge are $69 \%$ of the values calculated by Yonkin et al. and Klien et al. (Figure 1). Thus, the electrical energy use $\left(N_{\text {WWTP }}\right)$ at an "average" WWTP is $0.40 \mathrm{kWh} / \mathrm{m}^{3}$. We will use this value for $N_{W W T P}$ for the remainder of the paper.

Note that the purpose of this paper is to provide a framework that will aid in developing a quantitative understanding of the conditions needed for an MFC to achieve energy-neutral treatment. Simplifying assumptions were made in this initial effort, such as the relative amount of oxygen needed for $\mathrm{NH}_{3}$ oxidization was held constant at $37 \%$, and the MFCs normalized energy utilization was held constant regardless of volume. However, Equation (8) is flexible in that it allows each term to be modified according to site-specific conditions. For example, the $N_{W W T P}$ term can be modified on the left-hand side of Equation (8), which could be developed to quantify how MFC efficiency changes with volume, configuration, specific surface area (cathodic surface area/MFC volume), biofilm composition and other parameters. Additionally, the site-specific information pertaining to the relative amount of energy required to oxidize BOD for a given WWTP could also be used to further tune the $N_{W W T P}$ term. These adjustments are outside the scope of this paper but warrant further investigation. 


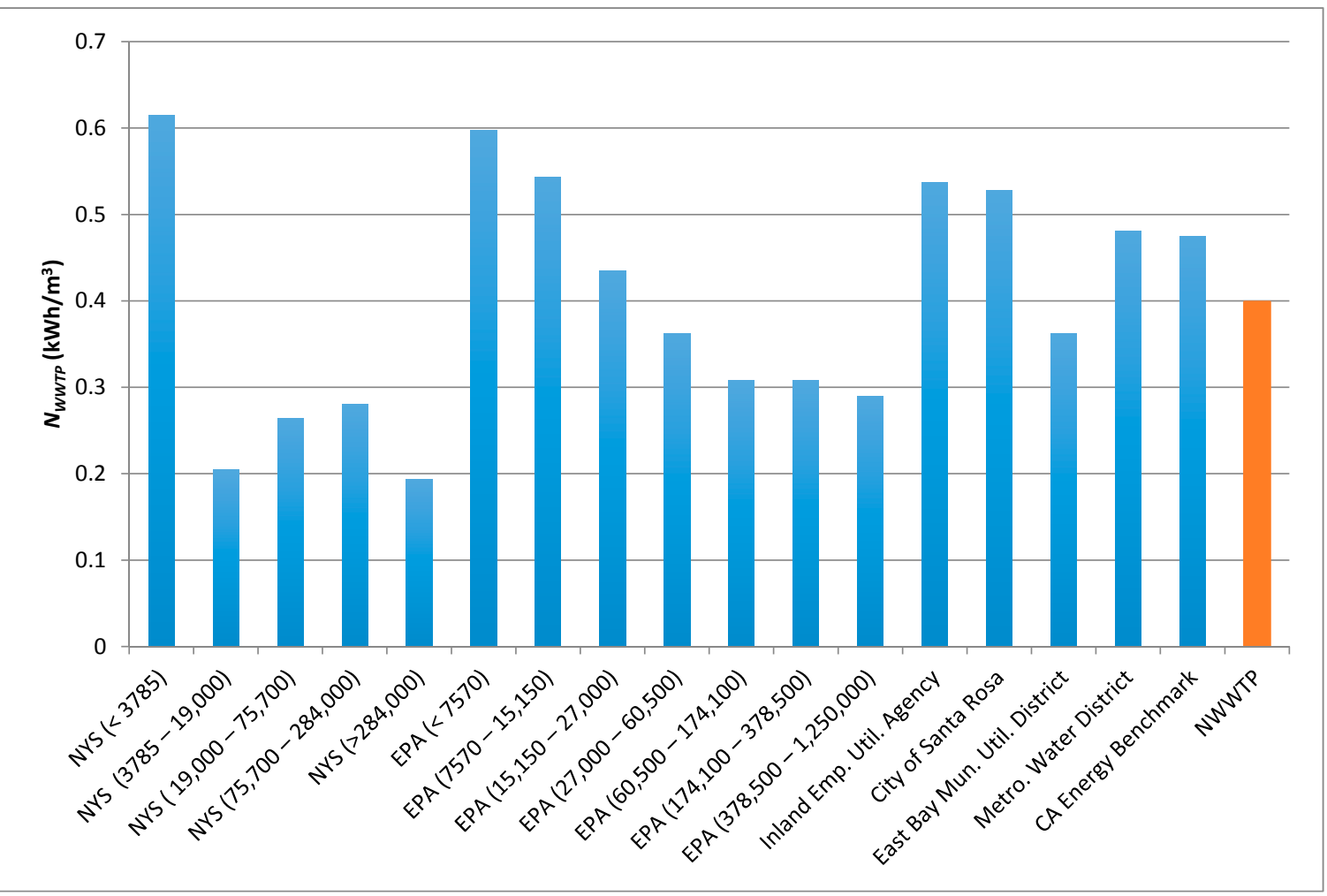

Figure 1. Energy consumption per unit volume $\left(N_{W W T P}\right)$ for a given wastewater treatment plant (WWTP). NYS, New York State; EPA, United States Environmental Protection Agency; CA, California. Values inside parentheses indicate flow $\left(\mathrm{m}^{3} /\right.$ day).

\subsection{Empirical Values for $E_{M F C}, \triangle C O D$ and $C E$ in MFC Studies Using Real Wastewater}

Literature values for $E_{M F C}, \triangle C O D$ and $C E$ are presented in Table 1 for MFCs that treat real wastewater. We chose to not to evaluate MFCs that treat synthetic wastewater because it is known that the biofilm composition is different in MFCs that use real wastewater [20], and that higher performance is generated with synthetic wastewater, typically with more negative anode potentials and less positive cathode potentials [21,22].

The fuel cell voltage is the difference between the anode potential and the cathode potential. The electrode material, operating temperature, electrode spacing/reactor configuration, wastewater composition and microbial community at each electrode influence the respective electrode potentials. As such, the $E_{M F C}$ values will vary study to study but tend to range between 0.17 and $0.50 \mathrm{~V}$, with an average of $0.32 \mathrm{~V}$, for MFCs treating real domestic wastewater. Higher voltages are not typically seen when treating wastewater so $E_{M F C}$ above $0.50 \mathrm{~V}$ may not be practical, with a major reason being that real wastewater (compared to synthetic wastewater) contains more complex organic compounds that take longer for the biofilm to degrade. Slower organic biodegradation rates indicate less COD is consumed over a given time period, thus the transfer of electrons to the anode is slower, which typically results in lower anode potentials and lower $E_{M F C}$.

In general, electrons (energy) liberated from a substrate can either be used for biosynthesis of cellular compounds (e.g., proteins/enzymes, lipids, DNA (deoxyribonucleic acid), sugars, etc.) or to create energy carrier molecules (e.g., ATP (adenosine triphosphate) and NADH (nicotinamide adenine dinucleotide)). It is the formation of latter compounds that require electrons be transferred down an electrochemical gradient within the cell to a terminal electron acceptor (i.e., ATP synthesis via the electron transport chain). In MFCs and other bioelectrochemical cells, the terminal electron acceptor is the anode. As such, the $C E$ is the fraction of electrons that are liberated from the substrate and transferred to the anode electrode. The remaining electrons do not get transferred to the anode as 
they are tied up in the other biochemical processes mentioned above. Literature values of the $C E$ for MFCs treating real wastewater range from $14 \%$ to $38 \%$, and have an average of $24 \%$. Lower CE values typically indicate that the exoelectrogens within the biofilm are using more of the energy extracted from the substrate for biosynthesis, not energy production, whereas higher CEs would indicate the opposite.

Table 1. Summary of typical MFC cell voltages $\left(E_{M F C}\right)$ and Coulombic Efficiencies $(C E)$ for MFCs treating real wastewater and assumed COD removals for high, medium and low strength wastewaters. Maximum Power Point values (MPP) are provided for reference.

\begin{tabular}{|c|c|c|c|c|c|c|c|}
\hline Parameter & Value & $\begin{array}{c}\text { P at MPP } \\
\left(\mathrm{W} / \mathrm{m}^{2}\right)\end{array}$ & $\begin{array}{c}\text { Volume } \\
\text { (mL) }\end{array}$ & $\begin{array}{l}\mathrm{COD}_{\mathrm{IN}} \\
(\mathrm{mg} / \mathrm{L})\end{array}$ & $\begin{array}{l}\triangle C O D \\
(\mathrm{mg} / \mathrm{L})\end{array}$ & Notes & Ref \\
\hline \multirow{4}{*}{$E_{M F C}(\mathrm{~V})$} & 0.17 & $2.4 \times 10^{-5}$ & 50 & 256 & 166 & SC-MFC; No membrane & [23] \\
\hline & 0.24 & $0.85 \mathrm{~mW}$ & 100 & 410 & - & $\mathrm{HRT}=8.8 \mathrm{~h} ; \mathrm{N} 1 \mathrm{C}$ config. & [24] \\
\hline & 0.27 & 0.95 & 7 & - & $92 \%$ & SC-MFC; $20^{\circ} \mathrm{C}$ config. & [25] \\
\hline & 0.28 & 1.20 & 7 & - & $92 \%$ & SC-MFC; $30^{\circ} \mathrm{C}$ config. & [25] \\
\hline \multirow{6}{*}{\multicolumn{2}{|c|}{$\begin{array}{l}0.30 \\
0.31 \\
0.33 \\
0.33 \\
0.34 \\
0.37 \\
0.40\end{array}$}} & 0.12 & 130 & 232 & - & SC-MFC; $R_{\text {ext }}=1000 \Omega$ & [27] \\
\hline & & $0.55 \mathrm{~mW}$ & 100 & 410 & - & $\mathrm{HRT}=8.8 \mathrm{~h} ; \mathrm{S} 2 \mathrm{C}$ config. & [24] \\
\hline & & 0.33 & 130 & 303 & - & SC-MFC; SEA config.; $R_{\text {ext }}=1000 \Omega$ & [28] \\
\hline & & 0.30 & 28 & 292 & - & $\mathrm{HRT}=4 \mathrm{~h} ; 2{ }^{\circ} \mathrm{C} ; \mathrm{Pt}$ cathode & [29] \\
\hline & & 0.32 & 170 & 545 & 447 & SC-MFC; Pt-NS; $\mathrm{R}_{\mathrm{ext}}=100 \Omega$ & [30] \\
\hline & & \multicolumn{5}{|c|}{ Average of literature values } & This study \\
\hline \multirow{14}{*}{$\mathrm{CE}$} & 0.13 & 0.89 & 130 & 210 & 59 & SEA-U config.; Pt cathode & [26] \\
\hline & 0.14 & - & 26 & 439 & - & SC-MFC; HRT $=2 \mathrm{~h} ; \mathrm{R}_{\mathrm{ext}}=1000 \Omega$ & [31] \\
\hline & 0.14 & - & 4000 & 280 & 196 & Tubular MFC & [32] \\
\hline & 0.15 & 1.20 & 7 & - & $92 \%$ & SC-MFC; $30^{\circ} \mathrm{C}$ config. & [25] \\
\hline & 0.17 & 0.95 & 7 & - & $92 \%$ & SC-MFC; $20^{\circ} \mathrm{C}$ config. & [25] \\
\hline & 0.17 & 0.15 & 140 & 410 & 193 & SC-MFC; HRT = $2.2 \mathrm{~h}$; N1C config. & {$[24]$} \\
\hline & 0.18 & 0.10 & 140 & 410 & 134 & SC-MFC; HRT = 2.2 h; S2C config. & [24] \\
\hline & 0.19 & 0.16 & 170 & 330 & 195 & SC-MFC; AC-CS; $R_{\text {ext }}=300 \Omega$ & [30] \\
\hline & 0.22 & - & 26 & 439 & - & SC-MFC; HRT $=2 \mathrm{~h} ; \mathrm{R}_{\mathrm{ext}}=100 \Omega$ & [31] \\
\hline & 0.31 & 0.14 & 140 & 410 & 221 & SC-MFC; HRT = 4.4 h; N1C config. & [24] \\
\hline & 0.31 & 0.33 & 130 & 303 & 182 & SC-MFC; SEA config.; $R_{\text {ext }}=1000 \Omega$ & [28] \\
\hline & 0.36 & 0.13 & 140 & 410 & 283 & SC-MFC; HRT = $8.8 \mathrm{~h} ; \mathrm{N} 1 \mathrm{C}$ config. & [24] \\
\hline & 0.38 & 0.30 & 28 & 292 & - & $\mathrm{HRT}=4 \mathrm{~h} ; 23^{\circ} \mathrm{C} ; \mathrm{Pt}$ cathode & [29] \\
\hline & 0.24 & \multicolumn{5}{|c|}{ Average of literature values } & This study \\
\hline \multirow{3}{*}{$\begin{array}{l}\mathrm{COD}_{\mathrm{IN}} \\
(\mathrm{mg} / \mathrm{L})\end{array}$} & 2250 & \multirow{3}{*}{\multicolumn{5}{|c|}{$\begin{array}{l}\text { Assumed value for high strength WW } \\
\text { Assumed value for medium strength WW } \\
\text { Assumed value for low strength WW }\end{array}$}} & This study \\
\hline & 750 & & & & & & This study \\
\hline & 250 & & & & & & This study \\
\hline $\begin{array}{l}\text { COD }{ }_{\text {OUT }} \\
(\mathrm{mg} / \mathrm{L})\end{array}$ & 100 & \multicolumn{5}{|c|}{ Assumed lower limit of MFC COD removal } & {$[31,34-36]$} \\
\hline \multirow{3}{*}{$\begin{array}{c}\triangle C O D \\
(\mathrm{mg} / \mathrm{L})\end{array}$} & 2150 & \multirow{3}{*}{\multicolumn{5}{|c|}{$\begin{array}{l}\text { Assumed value for COD removal with high strength } \mathrm{WW} \text { as the substrate } \\
\text { Assumed value for COD removal with medium strength } \mathrm{WW} \text { as the substrate } \\
\text { Assumed value for COD removal with low strength } \mathrm{WW} \text { as the substrate }\end{array}$}} & This study \\
\hline & 650 & & & & & & This study \\
\hline & 150 & & & & & & This study \\
\hline
\end{tabular}

Notes: SC, single chamber; TC, two chamber; ETFE, ethylene tetrafluoroethylene; HRT, hydraulic retention time; SPA, spaced electrode assembly; $R_{\text {ext }}$, external resistance; SEA, separator electrode assembly; SPA, closely spaced electrodes; S2C, a full brush evenly spaced between two cathodes; N1C, trimmed brush anodes near a single cathode; Pt, Platinum; NS, no separator; AC-CS, activated carbon cathode/cloth separator; DWW, domestic wastewater; CEM, cation exchange membrane; AC-CS, activated carbon cathode with cloth separator; Pt-NS, Pt cathode with no separator. 
Several studies have shown that power density decreases significantly at COD concentrations below $100 \mathrm{mg} / \mathrm{L}$ [31,34-36]. As such, we assume the treated effluent COD is $100 \mathrm{mg} / \mathrm{L}$ and assume a high $(2250 \mathrm{mg} / \mathrm{L})$, medium $(750 \mathrm{mg} / \mathrm{L})$ and low-strength wastewater $(250 \mathrm{mg} / \mathrm{L})$. Examples of high-strength wastewaters ( $>2000 \mathrm{mg} / \mathrm{L}$ COD) include industrial wastes such as brewery, and food processing wastewater, as well as centrate streams in WWTPs. Medium and low-strength wastewaters include various domestic wastewaters.

\subsection{Electrical Energy Generation from an MFC Using Average Values at Fixed CODs}

In this section, we begin testing the model by using literature values for the right-hand side of Equation (8) ( $E_{M F C}, C E$, and $\triangle C O D$ ) to solve for values of $N_{W W T P}$ and compare our calculated values with the average $N_{\text {WWTP }}$ value of $0.40 \mathrm{kWh} / \mathrm{m}^{3}$ calculated in the section above. Values of $N_{W W T P}$ were calculated at the three high, medium and low $\triangle C O D$ concentrations $(2150,650$ and $150 \mathrm{mg} / \mathrm{L})$ using Equation (8) and the average of the literature values for $E_{M F C}(0.32 \mathrm{~V})$ and $C E(0.24)$. The $N_{W W T P}$ for the high, medium and low-strength wastewaters is calculated to be $0.55,0.17$ and $0.04 \mathrm{kWh} / \mathrm{m}^{3}$, respectively. In comparison to the average energy utilization of $0.40 \mathrm{kWh} / \mathrm{m}^{3}$, only the high-strength wastewater would contain enough energy to offset a WWTP's energy requirements, if averaged $E_{M F C}$ and $C E$ values are used.

Equation (8) could be used to calculate the $E_{M F C}$ and $C E$ that the MFC would need to be energy-neutral $\left(0.40 \mathrm{kWh} / \mathrm{m}^{3}\right)$ and check if these values seem reasonable. As such, assuming medium strength wastewater $(\triangle C O D=650 \mathrm{mg} / \mathrm{L})$, the $E_{M F C}$ and $C E$ would need to increase such that their products equaled 0.18 . This could be accomplished by generating higher voltages $\left(E_{M F C}=0.77 \mathrm{~V}\right.$ and $C E=24 \%)$, being more efficient $\left(E_{M F C}=0.32 \mathrm{~V}\right.$ and $\left.C E=57 \%\right)$ or a combination of both $\left(E_{M F C}=0.50 \mathrm{~V}\right.$ and $C E=37 \%$ ) to obtain a $N_{W W T P}$ of $0.40 \mathrm{kWh} / \mathrm{m}^{3}$. According to our literature review summarized in Table 1, the ranges of $E_{M F C}$ and $C E$ are within what is typically seen (albeit at the higher end) indicating medium strength wastewaters could contain sufficient amounts of organics and that MFCs could attain high enough performance under these conditions to achieve energy-neutral treatment.

Taking the same approach as above but for the low strength wastewater $(\triangle C O D=150 \mathrm{mg} / \mathrm{L})$, achieving energy neutral treatment would require that the product of the $E_{M F C}$ and $C E$ equaled 0.80. At an average $E_{M F C}$ of $0.35 \mathrm{~V}$, achieving energy neutral treatment (at $0.40 \mathrm{kWh} / \mathrm{m}^{3}$ ) is not possible, even at $100 \%$ CE. Similarly, at an $E_{M F C}$ of $1 \mathrm{~V}$ (a value not typically seen even with synthetic wastewater), the $C E$ would need to be at least $80 \%$, which is beyond the range of $C E$ s observed when treating real wastewater. Researchers have obtained $C E$ s greater than $70 \%[37,38]$ but experiments were performed with acetate.

It is important to note that we assume each of the variables is independent of each other, however, it may be the case that altering one parameter (the voltage, for example) may influence the $C E$, and could shift the biofilm and/or the substrate biodegradation rate (thus, the COD removed at steady-state). The interplay phenomenon reported by Stoll et al. [21] highlights the concept that the MFCs tend towards an equilibrium given the environmental conditions at the anode and cathode electrodes: increasing the MFC's performance in one aspect (i.e., improving the anode potential), adversely affects a separate aspect of the MFC at the same time (i.e., decreases the cathode potential). One study by Sluetels et al. found that increasing the anode potential and decreasing the substrate concentration when feeding acetate improved the CE [39], however, to our knowledge, the interconnectivity of these parameters has not been quantified and, therefore, requires further investigation.

\subsection{COD Removal Requirements for Energy-Neutral Wastewater Treatment}

The previous section evaluated energy-neutral requirements at fixed $\triangle C O D$ values using Equation (8). In this section, we use Equation (9) to solve for an array of $\triangle C O D$ values and the corresponding $E_{M F C}$ and $C E$ values that would be needed to achieve energy neutral treatment at $0.40 \mathrm{kWh} / \mathrm{m}^{3}$. This exercise can be useful for trying to determine if a given wastewater stream 
has sufficient organics to achieve energy-neutral treatment while assuming reasonable $E_{M F C}$ and $C E$ values. In this analysis, we assume $E_{M F C}$ and $C E$ values range $0.2 \mathrm{~V}-0.7 \mathrm{~V}$ and $10 \%-50 \%$, respectively. The results are plotted in Figure 2.

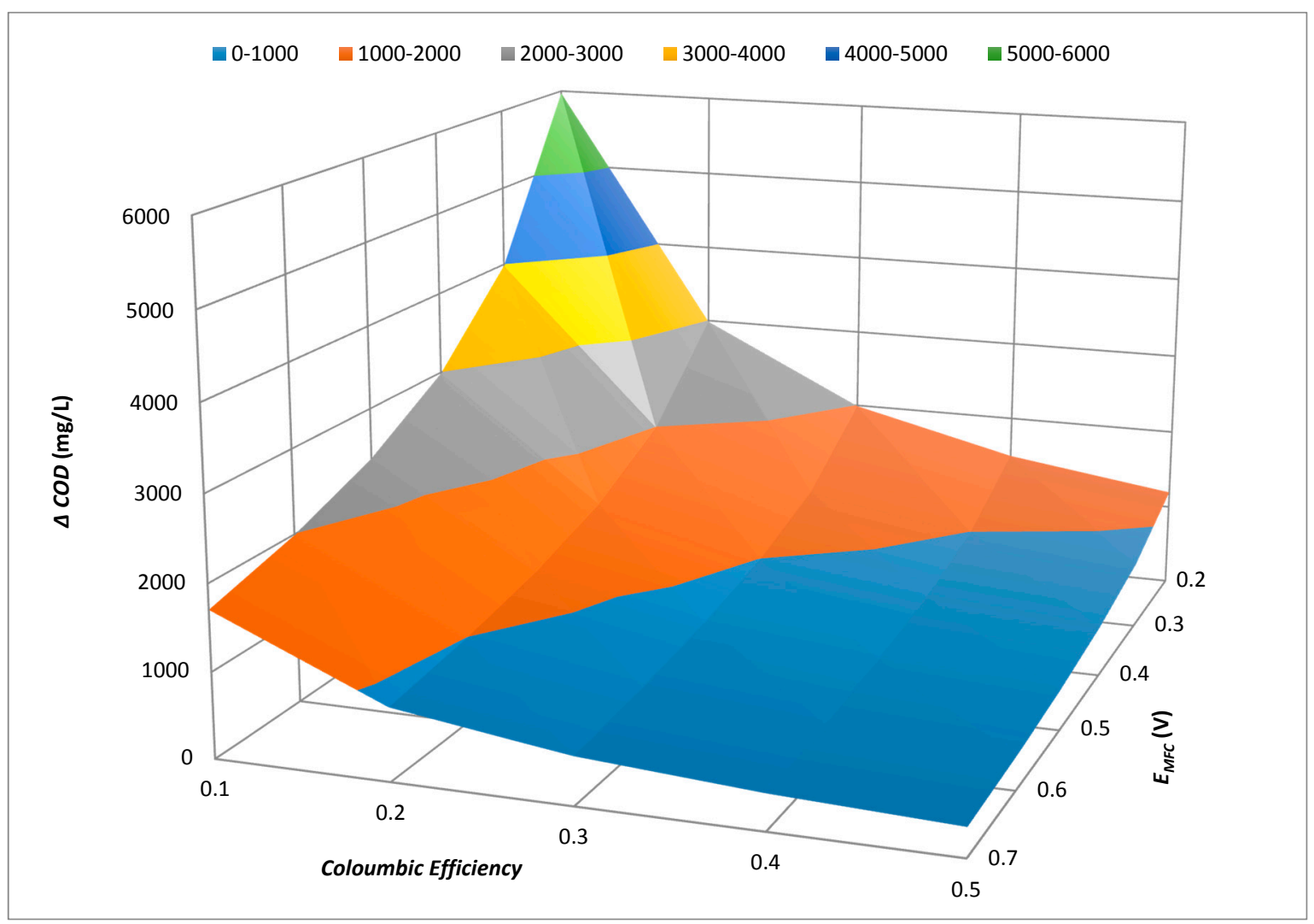

Figure 2. Contour map depicting the COD removal needed for energy-neutral treatment $(\triangle C O D)$, MFC voltage $\left(E_{M F C}\right)$ and Coulombic Efficiency $(C E)$ required for an MFC to be energy-neutral. Colors indicate ranges of $\triangle C O D$, according to the legend.

As expected, MFCs with high $E_{M F C}$ and $C E s$ will require less COD removal to achieve energy neutral treatment and MFCs with low $E_{M F C}$ and $C E s$ will require more COD removal to achieve energy neutral treatment. Possibly less intuitive is that, because the $E_{M F C}$ and $C E$ terms are in the denominator of Equation (9), the equation takes the form of $y=\frac{1}{x} \cdot \frac{1}{y}$. Therefore, a linear decrease in either parameter $\left(E_{M F C}\right.$ or $C E$ ) while holding the other constant results in an exponential increase in $\triangle C O D$ required for energy neutral treatment. For example, if it is assumed that an MFC can achieve energy neutral treatment at $N_{W W T P}=0.40 \mathrm{kWh} / \mathrm{m}^{3}$ by removing $750 \mathrm{mg} / \mathrm{L} C O D$ at steady-state and has an $E_{M F C}$ of $0.4 \mathrm{~V}$ and a $C E$ of 0.4 , a $25 \%$ decrease in $E_{M F C}$ performance would result in an $E_{M F C}=0.3 \mathrm{~V}$ (holding $C E$ constant) and would require that $1000 \mathrm{mg} / \mathrm{L}$ be removed, a 33\% increase in the required COD removal. If both $E_{M F C}$ and $C E$ decrease linearly from their initial values, the result is an even larger increase in the COD removal required. For example, under the same scenario of $\triangle C O D=750 \mathrm{mg} / \mathrm{L}, E_{M F C}=0.4 \mathrm{~V}$ and $C E=0.4$ initially, a $25 \%$ decrease in both parameters corresponding to an $E_{M F C}=0.3 \mathrm{~V}$ and $C E=0.3$ would require a $\triangle C O D$ of $1325 \mathrm{mg} / \mathrm{L}$ to achieve the same energy output, a $77 \%$ increase. Conversely, linear changes in $\triangle C O D$ required for energy-neutral treatment would require relatively small changes in $E_{M F C}$ and $C E$. 


\subsection{Future Opportunities and Considerations}

The purpose of these examples is to demonstrate the utility of Equation (8), and to show that it is possible to calculate performance requirements for energy-neutral wastewater treatment under a given wastewater composition and a target energy generation per unit volume.

Thus far we have assumed steady-state conditions and constrained the model to calculate what the $\triangle C O D, E_{M F C}$ and $C E$ values are required for energy-neutral treatment. It is not likely that a full-scale MFC installed at a WWTP will experience steady-state conditions for a prolonged period of time. Diurnal variations and normal daily COD loading fluctuations at a WWTP will result in non-steady state behavior, and $E_{M F C}$ and $I_{S S}(C E)$ will most likely vary as well. Therefore, even if an MFC is able to achieve energy-neutral treatment at steady-state conditions as per Equation (8) or (9), fluctuations in COD loading will most likely cause $E_{M F C}$ and $C E$ to vary such that more or less energy is generated than required for energy neutral treatment, something that the equations were not originally intended to calculate. Of course, the energy generated by the MFC can be calculated using the right-hand side of Equation (8) and compared to the target energy utilization of the WWTP $\left(N_{W W T P}\right)$, but this process is cumbersome and is no longer takes a predictive approach that made Equations (8) and (9) useful.

In this paper we have assumed hypothetical MFCs that were operated independently of each other. This approach was used for simplicity in the modeling calculations but does not account for series/parallel operation and it is unknown what implications operating in these configurations have on $C E$ and biofilm properties.

We have also assumed that it is acceptable to comparing real world WWTP energy consumptions to lab and pilot-scale energy productions of an MFC. Although it is known that smaller scale systems typically generate more energy than larger scale systems, to our knowledge there are no data on performance metrics of full-scale MFCs at WWTPs. As such, a direct comparison was not possible. Regardless, if MFCs are to become viable systems, then their performance at larger scales will need to improve to offset the energy densities generated at real WWTPs.

If MFCs are to achieve energy-neutral or -positive treatment, all variables on the right-hand side in Equation (8) must be optimized. However, the extent in which the $C E$ and $E_{M F C}$ can be manipulated is still unknown. In the above discussion, we treated the parameters $E_{M F C}$ and $C E$ as variables; however, this suggests these parameters could intentionally be altered. This may not be the case though, and the user may not have control over when or how much these variables change. $E_{M F C}$ is the difference between the cathode $\left(E_{\text {cathode }}\right)$ and anode potentials $\left(E_{\text {anode }}\right)$. Environmental conditions, such as $\mathrm{pH}$ at the cathode surface and substrate concentration at the anodic biofilm surface, can influence the electrode potentials according to their respective Nernst Equation. Stoll et al. have demonstrated increasing $E_{M F C}$ by either adding acid to the cathode or using a more biodegradable substrate (acetate vs. wastewater) in the anode [21]. However, it was discovered that when wastewater was used as the substrate, interplay between the electrodes exists, whereby $E_{\text {cathode }}$ and $E_{\text {anode }}$ change as a function of the other: decreasing voltage losses at the cathode (decreased $\mathrm{pH}$ ) resulted in increased voltage losses at the anode, and vice versa. Although electrode conditions can be altered to generate more favorable electrode potentials, the system as a whole resists changes when the wastewater composition is altered in order to maintain equilibrium [21]. Because the $\mathrm{pH}$ of wastewater is circumneutral (between $\mathrm{pH} 6$ and 8) and interplay exists, it may be more accurate to consider $E_{M F C}$ as a constant for a given system that is dependent on the wastewater characteristics and fuel cell architecture/materials, and not as a variable that can be manipulated.

The $C E$ is the percent of electrons that are removed by the exoelectrogens and converted into electricity. It has been demonstrated that simple substrates lead to higher $C E$ than when domestic wastewater is used [31]. Additionally, studies have shown that the use of active energy harvesting devices instead of passive charge pumps can increase the $C E$. For example, when Wang et al. used a maximum power point controller (MPPC) instead of a charge pump, the CE increased from $0.7 \%$ to $15.6 \%$ [40]. This was attributed to the MPPC allowing the MFC to operate at an optimum external resistance. Beyond this, however, little is known and no methods or explanations exist that 
would inform a user how to manipulated the CE. More work is needed to better understand the extent in which the $C E$ can be altered to improve the system performance.

Although this paper focuses on organic matter removal, COD is not always the crucial parameter for the treatment of civil or industrial wastewater. The biological stage of a WWTP is often designed to accomplish the nitrogen cycle. Nitrogen rich effluents can be successfully treated by MFC, but this may imply a more complex system and additional costs, and, in any case, an electron consumption, thus determining a lowering of the CE. For example, Virdis et al. demonstrated MFCs could use nitrate as a cathodic electron acceptor, allowing for simultaneous removal of carbon (at the anode) and nitrogen (at the cathode) [41,42]. The process involves feeding the ammonium-containing effluent from the carbon-utilizing anode to an external biofilm-based aerobic reactor for nitrification, and then feeding the nitrified liquor to the MFC cathode for nitrate reduction using nitrite as cathodic electron acceptor.

In this paper, we assumed conservative ammonia concentrations for medium strength wastewater and the mass of oxygen required for oxidizing ammonia $\left(4.6 \mathrm{~kg} \mathrm{O}_{2} / \mathrm{kg} \mathrm{NH}_{3}\right)$ and calculated that approximately $37 \%$ of a WWTP's aeration requirements are for nitrogen removal. However, new nutrients management methods have been developed that can avoid or reduce the need for nitrogen removal [43], or recover nitrogen from wastewater using source separated treatment [44,45]. An alternative to complete nutrient removal is to retain nutrients in wastewater and use reclaimed water as a medium to convey valuable dissolved nutrients (i.e., nitrogen and phosphorous) for purposes such as agricultural and urban landscape irrigation. Farmers typically use fresh water and fertilizer to grow crops, but the downside of this approach is that producing fresh water and fertilizer are energy intensive processes. Altering or "tailoring" WWTPs to retaining desired concentrations of nutrients in the effluent (e.g., ammonia) allows for energy intensive processes, such as nitrification/denitrification, to be minimized, reducing the overall energy utilization rate. Given MFCs' ability to remove nitrogen is modest, the system may be well suited to generate tailored water.

\section{Conclusions}

The main motivation of this study was to develop a tool to quantify the minimum performance an MFC must achieve to be energy-neutral. By developing a simple model that accounts for the biofilm performance and efficiency (as $C E$ ), the wastewater characteristics $(\triangle C O D)$, the fuel cell performance (as $\left.E_{M F C}\right)$ and the electrical energy requirements at a WWTP $\left(N_{W W T P}\right)$, the feasibility of MFCs achieving energy-neutral wastewater treatment can be determined. Furthermore, this work provides qualitative and quantitative insights as to which parameters are important for maximizing power and energy outputs. Testing the model with values from the literature showed that MFCs are more capable of energy-neutral wastewater treatment at high influent CODs. Energy-neutral treatment is not likely possible when using low-strength wastewater because of the high $E_{M F C}$ and $C E$ required. Research that explores how the $E_{M F C}$ and $C E$ parameters can be manipulated to improve performance will be challenging but highly beneficial to improving overall performance. The framework described here will serve as a fundamental platform for realizing MFCs as a viable wastewater treatment technology, allowing users to reconcile energy-positive treatment with capital costs and effluent quality.

Acknowledgments: Support for this study was provided by the National Science Foundation Engineering Research Center Program under Cooperative Agreement EEC-1028968 (ReNUWIt), the Graduate Research Enhancement Grant (GREG) of New Mexico State University, and U.S. Geological Survey through the New Mexico Water Resources Research Institute.

Author Contributions: Zachary Stoll and Pei Xu designed and conducted the experiments. Pei Xu and Jan Dolfing worked with Zachary Stoll in writing and revising the paper.

Conflicts of Interest: The authors declare no conflict of interest. Any opinions, findings, conclusions or recommendations expressed in this publication are those of the authors and do not necessarily reflect the view of supporting organizations. 


\section{References}

1. Daw, J.; Hallett, K.; DeWolfe, J.; Venner, I. Energy efficiency strategies for municipal wastewater treatment facilities. Contract 2012, 303, 275-3000. Available online: https:/ / www.nrel.gov/docs/fy12osti/53341.pdf (accessed on 25 June 2017).

2. Carter-Jenkins, S. US EPA Press Release: EPA Tool Helps Communities Tap into Energy Savings. 2008. Available online: https:/ / www.epa.gov/sustainable-water-infrastructure/water-and-energy-efficiencyutilities-and-home (accessed on 5 July 2017).

3. United States Environmental Protection Agency (US EPA). Energy Efficiency in Water and Wastewater Facilities: A Guide to Developing and Implementing Greenhouse Gas Reduction Programs; US EPA: Washington, DC, USA, 2013.

4. Pabi, S.; Amarnath, A.; Goldstein, R.; Reekie, L. Electricity Use and Management in the Municipal Water Supply and Wastewater Industries; Electric Power Research Institute (EPRI): Palo Alto, CA, USA, 2014.

5. Dong, Y.; Qu, Y.; He, W.; Du, Y.; Liu, J.; Han, X.; Feng, Y. A 90-liter stackable baffled microbial fuel cell for brewery wastewater treatment based on energy self-sufficient mode. Bioresour. Technol. 2015, 195, 66-72. [CrossRef] [PubMed]

6. Heidrich, E.; Dolfing, J.; Scott, K.; Edwards, S.; Jones, C.; Curtis, T. Production of hydrogen from domestic wastewater in a pilot-scale microbial electrolysis cell. Appl. Microbiol. Biotechnol. 2013, 97, 6979-6989. [CrossRef] [PubMed]

7. Ge, Z.; He, Z. Long-term performance of a 200-liter modularized microbial fuel cell system treating municipal wastewater: Treatment, energy, and cost. Environ. Sci. Water Res. Technol. 2016, 2, 274-281. [CrossRef]

8. Jiang, D.; Curtis, M.; Troop, E.; Scheible, K.; McGrath, J.; Hu, B.; Suib, S.; Raymond, D.; Li, B. A pilot-scale study on utilizing multi-anode/cathode microbial fuel cells (mac $\mathrm{mfcs}$ ) to enhance the power production in wastewater treatment. Int. J. Hydrog. Energy 2011, 36, 876-884. [CrossRef]

9. Cusick, R.D.; Bryan, B.; Parker, D.S.; Merrill, M.D.; Mehanna, M.; Kiely, P.D.; Liu, G.; Logan, B.E. Performance of a pilot-scale continuous flow microbial electrolysis cell fed winery wastewater. Appl. Microbiol. Biotechnol. 2011, 89, 2053-2063. [CrossRef] [PubMed]

10. Feng, Y.; He, W.; Liu, J.; Wang, X.; Qu, Y.; Ren, N. A horizontal plug flow and stackable pilot microbial fuel cell for municipal wastewater treatment. Bioresour. Technol. 2014, 156, 132-138. [CrossRef] [PubMed]

11. Zhuang, L.; Yuan, Y.; Wang, Y.; Zhou, S. Long-term evaluation of a 10-liter serpentine-type microbial fuel cell stack treating brewery wastewater. Bioresour. Technol. 2012, 123, 406-412. [CrossRef] [PubMed]

12. Dong, Y.; Feng, Y.; Qu, Y.; Du, Y.; Zhou, X.; Liu, J. A combined system of microbial fuel cell and intermittently aerated biological filter for energy self-sufficient wastewater treatment. Sci. Rep. 2015, 5, 18070. [CrossRef] [PubMed]

13. Rittmann, B.E.; McCarty, P.L. Environmental Biotechnology: Principles and Applications; McGraw-Hill Book Co.: New York, NY, USA, 2001.

14. Huggins, T.; Fallgren, P.; Jin, S.; Ren, Z. Energy and performance comparison of microbial fuel cell and conventional aeration treating of wastewater. J. Microb. Biochem. Technol. S 2013, 6. [CrossRef]

15. Logan, B.E.; Hamelers, B.; Rozendal, R.; Schröder, U.; Keller, J.; Freguia, S.; Aelterman, P.; Verstraete, W.; Rabaey, K. Microbial fuel cells: Methodology and technology. Environ. Sci. Technol. 2006, 40, 5181-5192. [CrossRef] [PubMed]

16. Klein, G.; Krebs, M.; Hall, V.; O’Brein, T.; Blevins, B.B. California's Water-Energy Relationship; California Energy Commission: Sacramento, CA, USA, 2005.

17. Yonkin, M. Statewide Assessment of Energy Use by the Municipal Water and Wastewater Sector; New York State Energy Research and Development Authority: Albany, NY, USA, 2008.

18. Mulinix, S. Aeration 101-Back to Basics. 2012. Available online: http://awea-ar.org/images/downloads / 2012_Specialty_Conference_Presentations/aeration101_scott_mulinix_presentation_rev1.pdf (accessed on 4 August 2017).

19. Tchobanoglous, G.; Burton, F.; Stensel, H.D. Wastewater Engineering: Treatment and Reuse; Mc Graw Hill: New York, NY, USA, 2002.

20. Lee, J.; Phung, N.T.; Chang, I.S.; Kim, B.H.; Sung, H.C. Use of acetate for enrichment of electrochemically active microorganisms and their 16s rdna analyses. FEMS Microbiol. Lett. 2003, 223, 185-191. [CrossRef] 
21. Stoll, Z.A.; Dolfing, J.; Ren, Z.J.; Xu, P. Interplay of anode, cathode, and current in microbial fuel cells: Implications for wastewater treatment. Energy Technol. 2016, 4, 583-592. [CrossRef]

22. Stoll, Z.A.; Ma, Z.; Trivedi, C.B.; Spear, J.R.; Xu, P. Sacrificing power for more cost-effective treatment: A techno-economic approach for engineering microbial fuel cells. Chemosphere 2016, 161, 10-18. [CrossRef] [PubMed]

23. Christgen, B.; Scott, K.; Dolfing, J.; Head, I.M.; Curtis, T.P. An evaluation of the performance and economics of membranes and separators in single chamber microbial fuel cells treating domestic wastewater. PLoS ONE 2015, 10, e0136108. [CrossRef] [PubMed]

24. Kim, K.-Y.; Yang, W.; Logan, B.E. Impact of electrode configurations on retention time and domestic wastewater treatment efficiency using microbial fuel cells. Water Res. 2015, 80, 41-46. [CrossRef] [PubMed]

25. Cheng, S.; Xing, D.; Logan, B.E. Electricity generation of single-chamber microbial fuel cells at low temperatures. Biosens. Bioelectron. 2011, 26, 1913-1917. [CrossRef] [PubMed]

26. Ren, L.; Ahn, Y.; Logan, B.E. A two-stage microbial fuel cell and anaerobic fluidized bed membrane bioreactor (mfc-afmbr) system for effective domestic wastewater treatment. Environ. Sci. Technol. 2014, 48, 4199-4206. [CrossRef] [PubMed]

27. Ahn, Y.; Logan, B.E. Domestic wastewater treatment using multi-electrode continuous flow mfcs with a separator electrode assembly design. Appl. Microbiol. Biotechnol. 2013, 97, 409-416. [CrossRef] [PubMed]

28. Ahn, Y.; Hatzell, M.C.; Zhang, F.; Logan, B.E. Different electrode configurations to optimize performance of multi-electrode microbial fuel cells for generating power or treating domestic wastewater. J. Power Sour. 2014, 249, 440-445. [CrossRef]

29. Ahn, Y.; Logan, B.E. Effectiveness of domestic wastewater treatment using microbial fuel cells at ambient and mesophilic temperatures. Bioresour. Technol. 2010, 101, 469-475. [CrossRef] [PubMed]

30. Stager, J.L.; Zhang, X.; Logan, B.E. Addition of acetate improves stability of power generation using microbial fuel cells treating domestic wastewater. Bioelectrochemistry 2017, 118, 154-160. [CrossRef] [PubMed]

31. Zhang, X.; He, W.; Ren, L.; Stager, J.; Evans, P.J.; Logan, B.E. Cod removal characteristics in air-cathode microbial fuel cells. Bioresour. Technol. 2015, 176, 23-31. [CrossRef] [PubMed]

32. Zhang, F.; Ge, Z.; Grimaud, J.; Hurst, J.; He, Z. Long-term performance of liter-scale microbial fuel cells treating primary effluent installed in a municipal wastewater treatment facility. Environ. Sci. Technol. 2013, 47, 4941-4948. [CrossRef] [PubMed]

33. Karthikeyan, R.; Selvam, A.; Cheng, K.Y.; Wong, J.W.-C. Influence of ionic conductivity in bioelectricity production from saline domestic sewage sludge in microbial fuel cells. Bioresour. Technol. 2016, 200, 845-852. [CrossRef] [PubMed]

34. Zhuang, L.; Zheng, Y.; Zhou, S.; Yuan, Y.; Yuan, H.; Chen, Y. Scalable microbial fuel cell (mfc) stack for continuous real wastewater treatment. Bioresour. Technol. 2012, 106, 82-88. [CrossRef] [PubMed]

35. Akman, D.; Cirik, K.; Ozdemir, S.; Ozkaya, B.; Cinar, O. Bioelectricity generation in continuously-fed microbial fuel cell: Effects of anode electrode material and hydraulic retention time. Bioresour. Technol. 2013, 149, 459-464. [CrossRef] [PubMed]

36. Nam, J.-Y.; Kim, H.-W.; Lim, K.-H.; Shin, H.-S. Effects of organic loading rates on the continuous electricity generation from fermented wastewater using a single-chamber microbial fuel cell. Bioresour. Technol. 2010, 101, S33-S37. [CrossRef] [PubMed]

37. Fan, Y.; Hu, H.; Liu, H. Enhanced coulombic efficiency and power density of air-cathode microbial fuel cells with an improved cell configuration. J. Power Sour. 2007, 171, 348-354. [CrossRef]

38. Rozendal, R.A.; Hamelers, H.V.; Molenkamp, R.J.; Buisman, C.J. Performance of single chamber biocatalyzed electrolysis with different types of ion exchange membranes. Water Res. 2007, 41, 1984-1994. [CrossRef] [PubMed]

39. Sleutels, T.H.; Darus, L.; Hamelers, H.V.; Buisman, C.J. Effect of operational parameters on coulombic efficiency in bioelectrochemical systems. Bioresour. Technol. 2011, 102, 11172-11176. [CrossRef] [PubMed]

40. Wang, H.; Park, J.-D.; Ren, Z. Active energy harvesting from microbial fuel cells at the maximum power point without using resistors. Environ. Sci. Technol. 2012, 46, 5247-5252. [CrossRef] [PubMed]

41. Virdis, B.; Rabaey, K.; Yuan, Z.; Keller, J. Microbial fuel cells for simultaneous carbon and nitrogen removal. Water Res. 2008, 42, 3013-3024. [CrossRef] [PubMed]

42. Virdis, B.; Rabaey, K.; Rozendal, R.A.; Yuan, Z.; Keller, J. Simultaneous nitrification, denitrification and carbon removal in microbial fuel cells. Water Res. 2010, 44, 2970-2980. [CrossRef] [PubMed] 
43. Vuono, D.; Henkel, J.; Benecke, J.; Cath, T.Y.; Reid, T.; Johnson, L.; Drewes, J.E. Flexible hybrid membrane treatment systems for tailored nutrient management: A new paradigm in urban wastewater treatment. J. Memb. Sci. 2013, 446, 34-41. [CrossRef]

44. Tarpeh, W.A.; Barazesh, J.M.; Cath, T.Y.; Nelson, K.L. Electrochemical stripping to recover nitrogen from source-separated urine. Environ. Sci. Technol. 2018, 52, 1453-1460. [CrossRef] [PubMed]

45. Kavvada, O.; Tarpeh, W.A.; Horvath, A.; Nelson, K.L. Life-cycle cost and environmental assessment of decentralized nitrogen recovery using ion exchange from source-separated urine through spatial modeling. Environ. Sci. Technol. 2017, 51, 12061-12071. [CrossRef] [PubMed]

(C) 2018 by the authors. Licensee MDPI, Basel, Switzerland. This article is an open access article distributed under the terms and conditions of the Creative Commons Attribution (CC BY) license (http://creativecommons.org/licenses/by/4.0/). 